\title{
Chemical burns of the eye: causes and management
}

\author{
STEPHEN J MORGAN \\ From the Croydon Eye Unit
}

SUMmary For the 14 months 1 January 1985 to 28 February 1986 all cases of chemical eye injury presenting to the Croydon Eye Unit were analysed. Of the 180 cases 19 were caused by assaults and 14 were admitted for treatment. The wide range of injurious substances is emphasised, and the circumstances of injury are listed. A discussion of the management of chemical eye injury is included.

Chemical injuries of the eye form a small but significant fraction of ocular trauma. Three recent studies $^{1-3}$ put the incidence at $7,8 \cdot 7$, and $9 \cdot 9 \%$ of all ocular trauma, respectively. While many of these injuries are trivial, with no lasting adverse effects, others, notably those involving strong alkalis and to a less extent acids and other noxious substances, are potentially blinding. This study was prompted by a recent rise in the incidence of chemical trauma due to assault seen at Croydon Eye Unit, and set out to determine what substances are involved, which people are at risk, and the frequency of assault cases.

\section{Patients and methods}

The Croydon Eye Unit serves a largely residential area, population 300000 , with total attendances 33000 and new attendances 11000 per annum, based on 1984 figures.

Data were extracted from the case histories of all 180 cases of chemical eye injury presenting during the study period.

\section{Results}

Of 180 cases 136 were male and 44 female. Forty-one patients $(23 \%)$ suffered bilateral injuries. The age distribution (Fig. 1) shows a marked preponderance of people of young working age, especially ages 16 to 25.

The range of implicated substances (Table 1) is very large, there being at least 33 and probably many more chemical compounds. Three categories, alkalis $(26 \%)$, acids $(14 \%)$, and solvent based products $(13 \%)$, together accounted for over half the cases.

Correspondence to Dr S J Morgan, Newcastle General Hospital, Westgate Road, Newcastle upon Tyne, NE4 6BE.
Nineteen cases $(10 \cdot 6 \%)$ were the result of assaults. The injurious agent was ammonia in nine (possibly 10) and an antipersonnel gas in nine. Two of the assaulted persons had other injuries: both had cuts and bruises and one a fractured mandible. Circumstances and apparent motives for the assaults are detailed in Table 2.

One hundred and sixty-one cases $(89.4 \%)$ were the result of accidents. Some details of the history were lacking in 28 ; of the remainder $84(63 \%)$ had occurred at work, $44(33 \%)$ at home, $4(3 \%)$ at school, and one in a public house. In one case deliberate self injury was suspected. The occupations of those injured at work are listed in Table 3.

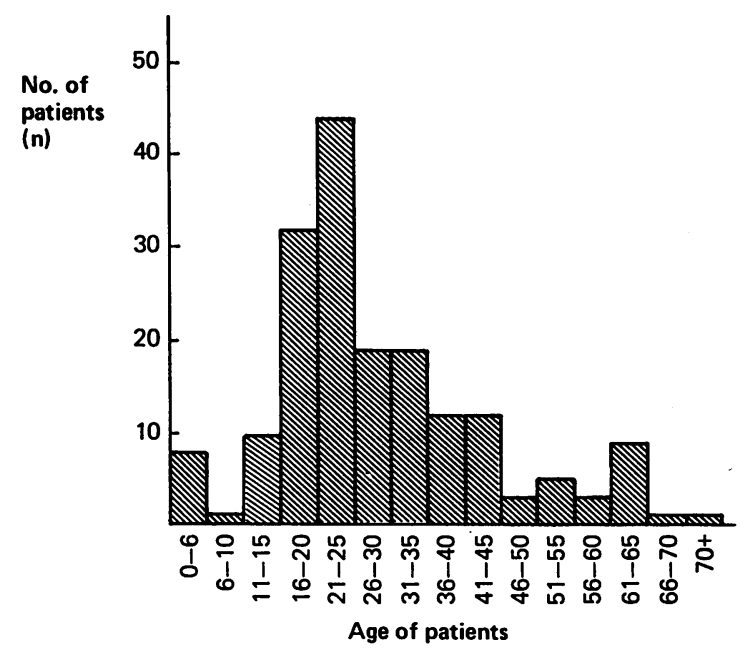

Fig. 1 Age distribution in 178 cases of chemical eye injury (age not recorded in two patients). 
Table 1 Injurious agent in 180 cases of chemical eye injury

\begin{tabular}{|c|c|c|c|}
\hline \multirow{2}{*}{$\frac{\text { Agent }}{\text { Alkalis }}$} & \multicolumn{2}{|c|}{ Number Subgroups } & $\begin{array}{l}\text { No } \\
14\end{array}$ \\
\hline & 47 & $\begin{array}{l}\text { Plaster } \\
\text { Ammonia } \\
\text { Oven cleaner/NaOH } \\
\text { Wet cement } \\
\text { Dry cement } \\
\text { Truck wash* }\end{array}$ & $\begin{array}{r}14 \\
10 \\
8 \\
8 \\
6 \\
1\end{array}$ \\
\hline Acids & 25 & $\begin{array}{l}\text { Carbattery } \\
\text { Miscellaneous } \\
\text { Gastric aspirate } \\
\text { Boron trifluoride }\end{array}$ & $\begin{array}{r}15 \\
8 \\
1 \\
1\end{array}$ \\
\hline Solvents/paints & 24 & & \\
\hline Detergents & 15 & & \\
\hline Antipersonnel sprays & 9 & & \\
\hline Adhesives & 9 & & \\
\hline Bleach & 7 & & \\
\hline Aerosols & 6 & & \\
\hline Surgical scrub & 5 & & \\
\hline Creosote & 5 & & \\
\hline Antifreeze & 3 & & \\
\hline Brake fluid & 3 & & \\
\hline Petrol & 3 & & \\
\hline Perfumes & 3 & & \\
\hline Copper sulphate & 2 & & \\
\hline Disinfectants & 2 & & \\
\hline Topical drugs & 2 & & \\
\hline Chilli Powder & 1 & & \\
\hline Contact lens cleaner & 1 & & \\
\hline Dispel (air freshener) & 1 & & \\
\hline Fire lighter fluid & 1 & & \\
\hline Gas canister & $1 \dagger$ & & \\
\hline Insecticide & 1 & & \\
\hline Methyl diphenyl isocyanate & 1 & & \\
\hline Mouthwash & 1 & & \\
\hline Phenytoin solution & 1 & & \\
\hline Tattooing fluid & 1 & & \\
\hline
\end{tabular}

*See text.

†Exact nature unclear.

\section{ADMITTED CASES}

Fourteen cases (six assaults and eight accidents) were admitted for treatment. All were males and their ages ranged from 14 to 53 . Eight were bilateral cases. Indications for admission were (1) severity of the injury, (2) presence of severe pain and blepharospasm, or (3) presence of other injuries.

All six assault cases were caused by ammonia; the other implicated substances were cement (4), and plaster, brake fluid, truck wash (a detergent/alkali mixture), and a gas canister (type unknown) one case each.

Corneal injury ranged from severe punctate keratopathy to $95 \%$ epithelial loss. In the two most severely injured eyes there were persistent stromal scars, albeit with normal visual acuity.

Conjunctival injury consisted of patchy or confluent areas of epithelial loss, with small ischaemic areas in a minority of cases and significant limbal ischaemia (up to $25 \%$ ) in four. Persistent subtarsal
Table 2 Breakdown of circumstances of 19 cases of chemical burn sustained as a result of malicious attacks

\begin{tabular}{lr}
\hline Occupation of victim & 2 \\
Sales assistant & 1 \\
Security officer & 1 \\
Van driver & 1 \\
British Rail steward & 1 \\
Petrol attendant & 13 \\
Not at work when attacked & 19 \\
Total & \\
Place of attack & 10 \\
Street & 2 \\
Shop & 1 \\
Train in motion & 1 \\
Outside bank & 1 \\
Petrol station & 1 \\
Public house & 1 \\
Night club & 2 \\
Unclear & 19 \\
Total & \\
Motive for attack & 6 \\
Robbery & 3 \\
Street fight & 3 \\
Petty quarrel & 7 \\
None apparent & 19 \\
Total &
\end{tabular}

Table 3 Occupations of 84 patients who sustained chemical eye injuries at work

Builders and labourers

Electricians

Engineers

Nurses

Cleaners

Machine operators

Hotel and catering

Plating and printing

Drivers

Painters

Plumbers

Storemen

Carpenter

Carvalet

Computer operator

Fireman

Glazier

Manager

Physiotherapist

Receptionist

Student

Total

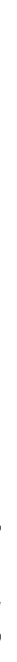

foreign bodies were found in six eyes. Minor lid burns were seen in three ammonia cases.

Treatment involved immediate and repeated lavage of the conjunctival sac with sterile saline until the $\mathrm{pH}$ approached neutral. Particles of foreign material were removed after double eversion of the lids. Topical steroids were given in all cases, and in 17 cases an intensive regimen $(1 / 2$ hourly to 2 hourly dexamethasone) was instituted. Topical vitamin C 
was applied in two cases and oral given in one. Mydriatics, analgesia, and padding were used as required.

The duration of stay in hospital ranged from one to 11 days determined by corneal re-epithelialisation and degree of discomfort. The total duration of treatment ranged from two days to $3 \frac{1}{2} 2$ months, tailing off according to clinical resolution.

Six patients defaulted from follow-up, and five had no sequelae and were discharged. One patient followed up elsewhere developed suspected functional visual loss in his fellow eye. Two patients had persistent corneal opacities but with normal visual acuities; one of these also had scarring of the upper tarsal plate without symblepharon.

NON-ADMITTED CASES

Of these 166 cases $110(66 \cdot 3 \%)$ were seen once only, $44(26 \cdot 5 \%)$ were followed up for up to one week, 11 $(6.6 \%)$ for up to two weeks and only one for more than two weeks. In 92 cases $(55.4 \%)$ topical steroids were used, often as a single dose of ointment plus an eye pad. In no case was any permanent injury observed.

ASSAULT VERSUS ACCIDENTAL CASES

Assault cases were over six times as likely to be admitted as accidental (31.6\% versus $4.97 \%$ respectively). Alkalis were involved in $52.6 \%$ of assault cases and $23.0 \%$ of accidental cases.

\section{Discussion}

This study indicates the range and severity of ocular chemical injuries which may be encountered in a district general hospital. It underlines the enormous variety of chemicals which may be implicated and the potentially serious nature of injuries due to assault. However, it also indicates the relative rarity of truly sight threatening injuries.

In the management of chemical injury, alkali burns continue to present the greatest therapeutic challenge, both in severity and in numbers. The property of alkalis which confers this significance is their ability to saponify cell membranes and rapidly penetrate the cornea, ${ }^{4}$ causing a rapid rise in anterior chamber $\mathrm{pH},{ }^{5}$ with resultant damage to iris, ciliary body, and lens. Vascular channels are also damaged (see below), leading to ischaemic injury. Acids in contrast fix and coagulate superficial tissues and fail to penetrate deeply into ocular structures. ${ }^{4}$

In comparison with American series ${ }^{36}$ the alkali burns reported in the present study are of only moderate severity. There were only four cases of significant limbal damage and no major visual loss in the affected eyes. The assessment of severity ${ }^{7}$ involves three factors: damage to the lids and adnexae, degree of limbal ischaemic necrosis (more than one-third affected equals severe), and the degree of acute corneal stromal opacification (not seen in the present study). The visual results of one of these series ${ }^{6}$ emphasise this difference: of 63 cases $40 \%$ had a final acuity of less than $6 / 60$ and $18 \%$ of no light perception; only $29 \%$ achieved an acuity better than 6/12. Two thirds of the cases in this series were assault victims, but the association with violent crime, alcoholism, and revenge attacks on unfaithful spouses contrasts with the motives of theft, petty quarrels, and gratuitous attacks seen in the present study.

Apart from motive, another factor influencing the outcome might be the nature or concentration of the noxious agent used.

In the management of chemical eye injury, first aid is of paramount importance. Immediate and copious irrigation with bland sterile solutions and removal of all solid particles should always precede a full history and examination. Testing the $\mathrm{pH}$ of the conjunctival sac or washings should indicate the presence of alkali, and, if it is present, irrigation should be prolonged. This gradually leaches alkali out of the tissues, where it would otherwise persist and cause further damage long after the $\mathrm{pH}$ of the external eye has returned to normal. ${ }^{4}$

In the early clinical assessment of assault cases a most important differential diagnosis exists between ammonia and antipersonnel agents such as CS gas. The picture is often confused by the assumption by victims and witnesses that any pungent smelling substance thrown at the face is ammonia. The following observations from personal experience may be helpful.

Antipersonnel agents are usually carried in an aerosol. They produce an intense choking with salivation, lacrimation, coughing, and a hot tingling sensation of all exposed skin. There is marked blepharospasm and photophobia. However, ocular examination reveals only a mild erythema of the skin and mild non-specific conjunctival injection with chemosis and epiphora. There may be slight punctate staining; otherwise all epithelium is intact. Full recovery from all effects occurs within hours.

The favourite vehicle for ammonia in this author's experience is the 'Jif lemon'. It produces a concentrated jet which the assailant can aim with great accuracy. The smell is characteristic but there is little systemic upset. The eyelids and skin may show blistering and erythema similar to superficial thermal burns. In milder burns the ocular signs are of injection and chemosis of the conjunctiva and geographical corneal and conjunctival epithelial loss, usually, due to Bell's phenomenon, on the infero- 
nasal aspect of the globe. These areas stain with fluorescein and rose Bengal, and there may be more extensive areas of punctate staining. In more severe burns the conjunctiva and episclera are blanched, and microscopic examination shows disruption of the blood column (cattle trucking) in the vessels. Extensive blanching produces a deceptively white eye, but the end result is ischaemic necrosis leading to conjunctival scarring, symblepharon, and a dry eye, and, where the limbus is involved, to persistent corneal ulceration, thinning, and early or late perforation. In the most severe cases there is corneal opacification, intense exudation into the anterior chamber with flare, cells, and even hypopyon, and cataract formation. There may be an acute pressure rise due to shrinkage of corneal collagen. ${ }^{8}$

In the treatment of the mildest alkali burns topical steroid/antibiotic ointment plus padding may be all that is required, but, in cases involving significant epithelial loss, steroids and mydriatics should be intensively applied. $10 \%$ potassium ascorbate, thought to act by scavenging free radicals released by degranulating polymorphs ${ }^{4}$ and to reverse a local alkali induced scorbutic state, ${ }^{9}$ can be given topically every one to two hours. Application is painful. Citric acid chemotactically inhibits polymorphs and reduces the incidence of corneal ulceration in experimental studies. ${ }^{10}$ The collagenase inhibitors L-cysteine and acetylcysteine have also been used. In extreme alkali burned. eyes the former had some beneficial effect ${ }^{11}$ while the latter did not. ${ }^{12}$

Persistent or recurrent corneal epithelial defects may be treated with therapeutic soft contact lenses, but care must be taken to ensure adequate tear volume and quality. ${ }^{3}$

In the longer term surgery on the lids, conjunctiva, and cornea may be required. In the worst cases a full thickness corneoscleral graft may be attempted, but the prognosis for the restoration of useful vision is often poor.

The alkali burns in this series all re-epithelialised well. The beneficial early effects of steroids in reducing the inflammatory reaction were evident, but the reported harmful later effects in promoting corneal melting and perforation by impairing the repair process $^{3}$ were not seen.

This may again reflect the absence of really severe injuries from this series. It is unproved whether withholding steroids would in fact have led to significant visual loss, but in the absence of evidence to the con- trary it would seem reasonable to encourage their intensive topical use in all but the most severe burns, at least for the first few days after injury.

In Croydon admissions due to chemical eye injury appear to be on the increase. In 1982 there were seven cases (five accidental), in 1983 one, in 1984 two, in 198512 , and in the first six months of 1986 eight cases. The proportion due to assaults is also increasing, which presumably reflects the rise in all crime. Whether chemical injury as a whole is increasing is not clear, but this study shows that a large number of cases must be preventable by the provision and use of adequate eye protection at work. Men of young working age are clearly the most at-risk group, and may be the most resistant to the use of this kind of protection. While the majority of cases are likely to be minor, where significant injury has occurred early and correct management may secure a good prognosis and minimise long term sequelae.

My thanks to Mr P J Holmes Sellors, Mr M D O'Riordan, and Miss H C Seward for allowing me to report patients under their care.

\section{References}

1 Jones NP, Hayward JM, Khaw PT, Claoue CMP, Elkington AR. Function of an ophthalmic 'accident and emergency' department: results of a six month survey. $\mathrm{Br}$ Med J 1986; 292: 188-90.

2 Vernon SA. Analysis of all new cases seen in a busy regional centre ophthalmic casualty department during a 24 week period. $J$ R Soc Med 1983; 76: 279-82.

3 Pfister RR. Chemical injuries of the eye. Ophthalmology 1983; 90: 1246-53.

4 Wright P. The chemically injured eye. Trans Ophthalmol Soc UK 1982; 102: 85-7.

5 Paterson CA, Pfister RR, Levinson RA. Aqueous humor $\mathrm{pH}$ changes after experimental alkali burns. Am J Ophthalmol 1975; 79: 414-9.

6 Klein R, Loben LA. Ocular alkali burns in a large urban area. Ann Ophthalmol 1976; 8: 1185-9.

7 Pfister RR, Koski J. Alkali burns of the eye: pathophysiology and treatment. South Med J 1982; 75: 417-22.

8 Paterson CA, Pfister RR. Intraocular pressure changes after alkali burns. Arch Ophthalmol 1974; 91: 211-8.

9 Pfister RR, Paterson CA. Ascorbic acid in the treatment of alkali burns of the eye. Ophthalmology 1980;87: 1050-7.

10 Pfister RR, Haddox JL, Paterson CA. The efficacy of sodium citrate in the treatment of severe alkali burns of the eye is influenced by the route of administration. Cornea 1982; 1: 205-11.

11 Brown SI, Akiya S, Weller CA. Prevention of the ulcers of the alkali burned cornea: preliminary studies with collagenase inhibitors. Arch Ophthalmol 1969; 82: 95-7.

12 Pfister RR, Nicolaro ML, Paterson CA. Sodium citrate reduces the incidence of corneal ulceration and perforation in extreme alkali burned eyes-acetylcysteine and ascorbate have no favourable effect. Invest Ophthalmol Vis Sci 1981; 21: 486-90.

Accepted for publication 31 October 1986. 